\title{
The Influence of English Pronunciation System on Spelling Errors Among Saudi Students
}

\author{
Dheifallah Altamimi ${ }^{1} \&$ Radzuwan Ab Rashid ${ }^{2}$ \\ ${ }^{1}$ University college of Haqel, Tabuk University, Tabuk, kingdom of Saudi Arabia \\ ${ }^{2}$ Faculty of Languages and Communication, University Sultan Zainal Abidin, Terengganu, Malaysia \\ Correspondence: Radzuwan Ab Rashid, Faculty of Languages and Communication, University Sultan Zainal \\ Abidin, Terengganu, Malaysia. E-mail: radzuwanrashid@unisza.edu.my
}

Received: June 8, 2019 Accepted: July 3, 2019 Online Published: August 26, 2019

doi:10.5539/ijel.v9n5p193 URL: https://doi.org/10.5539/ijel.v9n5p193

\begin{abstract}
This paper discusses how English pronunciation system causes spelling errors among undergraduate Saudi students. The research participants were five students in English Language Department at Tabuk University and five English language lecturers from the same department. Semi-structured interviews designed for the lecturers and students, as well writing task distributed to the students were used to generate data for the study. The findings reveal that phonological differences between English and Arabic cause difficulty in the learners' spelling. The students strive to write words in a similar way to how they are pronounced as they are unaware of the rules of English pronunciation which is totally different from their mother-tongue. The confusion with English pronunciation system causes several spelling errors, such as the errors related to final [e], vowels, silent letters and double consonants. This paper concludes that the Arab students need to be familiarized with English pronunciation system and they need to be made aware that English words are not necessarily spelt as how they are pronounced, which is in contrast to their mother tongue.
\end{abstract}

Keywords: spelling learning, EFL learns, phonological awareness

\section{Introduction}

Learning a foreign language always involves a number of challenges especially in the initial phases of learning where learners make linguistic, syntactic, semantic and phonological errors. These errors are a by-product of learning the language and are indicators of learning; the level of such errors indicates the phase of learning the learners are at (James, 2013; Almatarneh et al., 2019). Conducting a systematic analysis of learners' errors helps the understanding of their needs to learn the language in the best and fastest way. This analysis can further help design curricula, teaching plans and methods, and ways to reduce or eliminate the difficulties identified.

Writing is a key method that enables an individual to express his/her feelings or thoughts when they cannot be spoken. It transfers the sounds that can be heard into the words which can be read and seen. Enhanced literacy requires more than basic reading and writing skills; it also demands the correct spelling of words. However, this pivotal component of writing is challenging for many students, especially Arabic-speaking students learning English. These learners are unable to spell English words correctly, in the majority of cases; as they consider English as only a second, unimportant language, they tend not to develop a command of the pronunciation and spelling of words.

During the process of learning, the speaker hears sounds different to those she/he instinctively knows and has to form hypotheses about their use. Learners of a foreign language can have implicit knowledge about the orthographic structure of the target language insofar as they may be able to pronounce or spell a word in their foreign language without having explicit knowledge of the particular rule they are using. Poor spelling not only makes a bad impression; it also inhibits communication as the reader has to puzzle over the writer's message (Alsaawi, 2015).

In contrast to native speakers, who learn language systems naturally, Arab students may be unaware of the rules of English pronunciation, so produce the wrong letters (Alsaawi, 2015). This can be illustrated with an example of consonants. The students may not know when to write $g, c$ or $t$ since they are sometimes pronounced in the same way. For example, they may write recognize as recocknize, special as spetial or traditional as tradisional. 
Another example is where they might be confused between the use of /e/ or /i/ and spell divided wrongly as devised and decided as dicided. Their unawareness of the actual system of English may also lead the students to omit the vowels from the middle words, such as missing the first $e$ from interesting and spelling it as intresting, or seventh as sevnth. They may also make spelling mistakes by substituting one sound for another, such as writing quickly as cuickly.

Different languages have different linguistic features and therefore, it is difficult for learners especially Saudi learners who learn English as a foreign language to learn English easily or without any support (Al-jarf, 2015). This can be illustrated by a very simple example; sentences in Arabic start from right to left, whereas English goes from left to right. Furthermore, Arabic written and spoken forms have more correspondence and follow a relatively more regular pattern than English, for instance, the words make and man both have written $a$ in common but their pronunciation is different.

\section{Literature Review}

The concept of spelling has been defined differently by various researchers over the years. Puspandari (2017) defines spelling as a process of representing the spoken language in a written form that consists of a sequence of letters composed to form words in their generally accepted usage. On the other hand, Mpiti (2012) defines spelling as a process that encompasses a number of skills: phonological, morphological, syntax and semantic knowledge, as well as the ability to formulate words on the basis of visual memory along with applying the orthographic rules. Moreover, Perveen and Akram (2014) define spelling as the method for writing words in their correct and acceptable forms. In other words, it is a process of assembling the letters of a given language in accordance with their correct sequence according to the official orthographical rules of that language otherwise; it would be viewed as a spelling error.

Spelling errors can be the result of omission, substitution, insertion, or the misplacement of a letter when writing a particular word. Omission errors are where the student does not complete a word something is left out. Derivation errors occur when student does not apply a basic rule or follow the basic instructions for spelling a particular word, for instance, they write snobish for snobbish. Inflection errors occur when the student ignores or does not make the necessary changes when adding the inflection. For instance, students forget to drop or remove "e" when adding "ing" to some words, producing timeing for timing or reduceing for reducing. Residue error is when students forget to drop letters in a particular context like bite when the past form bit is required. Phonetic errors are produced when students spell words as they are spoken, like yot for yacht or wacht for watched.

\subsection{Linguistic Differences Between English and Arabic}

There are number of distinct linguistic features and differences between English and Arabic, resulting in several challenges for the Arab student wishing to acquire the English language. One of the major differences is the diversity within the orthographic systems (Altamimi et al., 2018). Shintani and Ellis (2013) note that Arab English language learners face great difficulty due to the difference between the relative regularity of the primarily phonetic-based Arabic script compared with the system of English spelling. It was pointed out earlier that English writing system links to borrowings from other languages which result in irregularities that sometimes even cause confusion to native English students (Fadda, 2012). In contrast, the Arabic writing system is more closely related to its phonetic system. The L1 background of Arab students influences them to look for sound-symbol correspondences in English words that do not always exist, and do not anticipate other differences. For instance, double letters and silent letters do not exist in the Arabic language, and that creates confusion while writing and pronouncing word in English (Saigh \& Schmitt, 2012).

Further, Sawalmeh (2013) observes that most aspects of written English cause difficulties for Arabic students. Arabic is recognized as a cursive (linked) system so that words are rarely represented as individual units; on other hand, in English, each word can be written separately and have individual identity (though as a Germanic language, meaning is conveyed through word bundles of up to around five individual words). It is very unusual to perceive each letter of Arabic as a separate unit like the English alphabet. Similarly, Alghonaim (2014) also mentions the difference in the writing system as one of the major causes of spelling errors made by Arabic students. Arabic writing runs from right to left, which leads Arabic students to misspell or misread words, especially mirror letters such as "b" and "d" and "p" and "q". This also make the eye movements move in the wrong direction so the students read words with the same letters incorrectly, like from instead of form (Al-Khairy, 2013).

To understand spelling errors, Solati (2014) points out the phonological differences between English and Arabic that cause difficulty in pronunciation. The study found that many Arab students strive to write words in a similar way to how they are pronounced, as in Arabic. Arabic has no phonemic difference between " $b$ " and "p"; the 
students tend to mix the two randomly in their spelling, which can cause major errors. For instance, Arabic students often write blaying instead of playing. In UAE, students from different Arab countries study in the public universities of Egypt, Somalia, the Emiratis, Tunisia, and Palestine and all tend to have difficulty managing new languages in both their verbal and written forms (Khansir \& Shahhoseiny, 2013).

\subsection{Phonological Awareness}

Phonological awareness is the awareness of sounds in spoken (not written) words indicated by the ability to make rhymes match initial consonants, and count the number of phonemes in spoken words (Gillon, 2017). Bourassa and Treiman (2009) define phonological awareness as the ability to identify sounds in spoken words. Hence, phonological awareness is seen as the explicit knowledge of the sound system of a given language (Santoro, Coyne, \& Simmons, 2006). Reed, Petscher and Foorman (2016) point out those phonological skills are an important consideration in teaching modern languages, because they provide support in the early reading activities of a given language.

At least some ability to distinguish phonological elements smaller than syllables seems to be necessary to make use of an alphabetic orthography (Gough, Juel, \& Griffith, 1992). Phonological awareness appears to be intimately tied to learning an alphabetical writing system. Stanovich (2000) calls the discovery of this link one of the rare success stories in modern cognitive developmental psychology. However, many questions remain about the nature of phonological awareness itself and its relationship to spelling and reading Bruck (1990), though phonological awareness and early reading links were established in the 1970s (Saiegh, Haddad, \& Taha, 2017). Anthony and Francis (2005) suggest that the position of a phoneme in a word is important. Initial phonemes are often easier to access than word-final phonemes, and this may influence spelling skills.

\subsection{Orthographic Knowledge}

Orthography refers to the conventional spelling system of a language. Languages have either deep or shallow orthographies. Those languages whose letters do not correspond directly to phonemes are orthographically deep, for instance, Arabic, English and Hebrew, while others whose letters correspond to phonemes are orthographically shallow, such as Finnish and Serbo-Croat (Cook, 2004). Apel (2011) suggests that orthographic knowledge is information retained in memory that tells us how to represent spoken language in written form. Spelling precision is the main measure of the quality of remembered orthographic information and thus knowledge of the English language (Martin-Chang, Ouellette, \& Madden, 2014; Ouellette, Martin-Chang, \& Rossi, 2017).

Moreover, orthographic knowledge entails knowing the rules for combining the letters of a language spelling is concerned with letter, not word sequences (Treiman \& Kessler, 2013). Bourassa and Treiman (2009) further explain English orthographic knowledge as the knowledge of legitimate and illegitimate letter sequences representing the sounds of English, that is, the use of spelling rules and patterns (Apel, 2011). It is further be seen as including the knowledge that governs alphabetical principles, for example, an /f/ sound can be ff, f, ph, as in different, first, and phone (Apel, 2008).

\subsection{Semantic Knowledge}

Semantic knowledge is "the knowledge of the effect of spelling on word meanings and vice versa" (Apel, 2008, p. 15). The ability to spell a word correctly is closely related to the ability to read it correctly. Reed, Petscher and Foorman (2016) claim that knowledge of spelling helps students have higher quality representations of words in both form and meaning, which improves their reading ability. Kertesz, Cancelliere and Bub (2017) argue, however, that oral reading is not mediated by semantic access, and suggest that written word pronunciation is a direct lexical connection between the orthographic and phonological representations. Wasowicz (2007) sees the relationship between morphological and semantic knowledge allows the individual to spell inflected words (for examples words that contain suffixes which provide information about time or quantity without changing the meaning, e.g., talk-talked, boy-boys) and derived forms (such as the words containing suffixes or prefixes that can change the meaning and sometimes the class of words, e.g., friend-friendly).

\subsection{Morphological Knowledge}

Morphological awareness is knowledge of the relationship between word forms and how they influence spelling (Bourassa \& Treiman, 2009). Morphology is an intricate linguistic domain that interacts with phonology and syntax in the organization of the mental lexicon (Saiegh, Haddad, \& Taha, 2017). Morphological awareness seems to produce improvements in reading and spelling in both developing and disabled readers (Bowers, Kirby, \& Deacon, 2010; Goodwin \& Ahn, 2010, 2013).

Lack of knowledge in linguistic differences especially in the areas of phonology, orthography, semantic, and 
morphology may cause confusion among the second/foreign language learners which will affect their ability to master the language.

\section{Methodology}

This research employs case study approach. Data were gathered from five students who are in the final year of their degree in English language at Tabuk University and five English language lecturers from the same University. The students and the lecturers were interviewed to know how English pronunciation causes spelling errors. All the recorded data were transcribed and codes were assigned accordingly. For example (S1) means student number 1 and (L2) means lecturer number 2. Data generation took place during the Semester One of the academic years 2017/2018.

In addition to the interviews, the students were asked to complete essay writing tasks involving two different topics (Advantages and disadvantages of the social media programs and The relationship between education and technology). They need to write for about 150 words for each topic.

\section{Findings}

\subsection{Students' Views}

Different students shared different comments or ideas toward the effect of English pronunciation on students' spelling errors. For example;

In English we don't write as we read or as we pronounce, which is in contrast to the writing system of Arabic in term of pronunciation (S1).

English pronunciation has different and difficult rules comparing to Arabic language which always lead us to make spelling rules (S2).

We make spelling mistakes because of the nature of English language, especially the differences in the number of alphabet letters of English and Arabic makes it hard to understand how to pronounce and spell certain words (S3).

From the responses shared by the three participants, it seems the differences between English and Arabic make it difficult for Saudi students to understand English pronunciation system and spell words in English correctly. Besides this, their spelling difficulties could be because of the English pronunciation system. Similar outcomes were found by Crompton's (2011) findings suggested that due to differences in Arabic and English language systems especially in the pronunciation system, students struggle to spell the words correctly.

In the similar vein, another participant associated the spelling errors with the difference in letters, sounds and pronunciation in the two languages (English and Arabic), as shown below.

The instance of the English letter "V" which is not found in Arabic where we do use another letter sounds like the letter "V". For example, we use the letter F instead of V, also in Arabic there is no silent letter, but in English there are many silent letters and this has caused our spelling mistakes (S4).

We have not known the correct pronunciation and writing system of English letters since our childhood, also the phoneme /e/ has no equivalent in Arabic and therefore there is a tendency to shift to /i/ which is quite close to Arabic pronunciation (S5).

The participants feel that, the differences between English and Arabic languages cause spelling problems in English, like the letters in English that do not exist in Arabic or are pronounced differently. Such differences affect the writing skills of Saudi students. English has many silent letters, which results in spelling errors too. Similar results came from a study by Khan (2011), and Farghaly and Shaalan (2009) using diagnostic analysis and natural language processing (NLP) to analyse common procedures for writing used by Arabic students in English and identifying their mistakes. The findings of these studies suggest that the common mistakes students make are due especially to silent letters or incorrect pronunciation of English words.

English is difficult for Saudi students because their early learning of English script and pronunciation was not well grounded so they turn to the familiar Arabic. Saudi students tend to make spelling mistakes because they mispronounce the phoneme /e/ as /I/ at the beginning of /elifənt/ and so may write/spell the word as iliphant instead of elephant. This is supported by Hameed and Aslam (2015) who gathered primary data through interviews, questionnaires and classroom observation. They suggest that, students make spelling mistakes due to confusing two vowels (e/i) when writing notes and during exams.

\subsection{Lecturers' Views}

The lecturers were asked several questions like how English pronunciation causes spelling errors and what are 
the main causes of students' spelling errors? Different lecturers shared different views. For example,

Spelling and pronunciation of certain English words is difficult because the pronunciation seems to be unrelated to actual spelling, which increases the students' difficulty in understanding basic instructions (L1).

The participant blamed the nature of English pronunciation when the spelling of a word is unrelated to the actual pronunciation. Malcolm (2009) had similar findings that the nature of English language writing and speaking (pronunciation) has no one to one relationship, in many cases.

Other participants pointed out that the increase in the number of silent letters or group of letters in English makes it hard for students to understand how to spell words or the link between pronunciation and spelling (e.g., L2). It is difficult for the students to understand the correct spelling due to the arbitrary rules of the English language pronunciation itself in terms of spelling (e.g., L3). This suggests that the complexity of the English language makes it difficult for learners. For instance, how vowels and silent letters are used, which is not how Arabic works. Malcolm (2009) also found that the use of silent letters and wide-ranging instructions make writing in English difficult.

The above findings suggest the rules of English language are illogical, which makes them complex and difficult for non-native speakers to understand English speaking and writing. Taha's (2007) mixed method research had similar findings, emphasising the complexity of spelling rules for EFL students which seem arbitrary and illogical.

While shading the light on the English pronunciation system two lecturers shared different views. For example, a lecturer blamed the different ways of pronouncing certain group of letters in English language, which can make spelling difficult (L4). Although the pronunciation of some words is simple, spelling them is another matter. Ghabool and Kashef (2012) found that some English words have the same sounds or the same spelling, but different meanings so it is difficult to memorize the spellings. For instance, both rough (adj, opposite of smooth) and $r u f f$ (n. a kind of pleated linen collar) sound the same: / $\mathrm{r} \wedge \mathrm{f} /$.

Another participant states that:

In English language one single sound can be represented by different letters or a combination of letters: for example: maid, made (L5).

English has many words that have the same sound but different meanings. For instance, bare, and bear, their, and there and so on. This makes it difficult for Arabic speakers to understand those words and use them in sentences. Jackson (2014) also stressed that most of the challenges for EFL students are due to the extremely complex English language rules and pronunciation. Perhaps the use of spell-checkers as recommended by Rimbar (2017) is useful to reduce the spelling errors produced by the students.

\subsection{Writing Task Analysis}

The common errors found in the writing task were nine different types: Vocalic transfer errors, Epenthesis errors, Consonantal replacement errors, Cluster simplification errors, Orthographic errors, Grapheme errors, missing letters, Phonological errors and Alteration errors. These nine types of the spelling errors were repeated by the same students in the two different topics.

The first writing task given to students was a 150 -word essay on the advantages and disadvantages of social media programs. Table 1 below represents the types and the frequency of each spelling error made by the students.

Table 1. Spelling errors in topic one

\begin{tabular}{llll}
\hline Types of Errors & Examples of Errors & $\begin{array}{l}\text { Number of Participants } \\
\text { committing the errors }\end{array}$ & Total Number of Errors \\
\hline Vocalic transfer errors & Defferent for Different & 5 & 50 \\
Epenthesis Errors & 4 & 44 \\
Consonantal Replacement errors & Combanies for Companies & 5 & 50 \\
Cluster Simplification errors & Polissy for Policy & 5 & 60 \\
Orthographic errors & Ferst for First & 3 & 30 \\
Grapheme errors & Serch for Search & 5 & 54 \\
Missing letters & Twetr for Twitter & 5 & 55 \\
Phonological errors & Velupment for Development & 5 & 60 \\
Alteration errors & Ustifiction for Justification & 4 & 38 \\
\hline
\end{tabular}


The second writing task given to students was a 150 -word essay on the relationship between education and technology. Table 2 below represents the types and the frequency of each spelling error made by the students.

Table 2. Spelling errors in topic two

\begin{tabular}{|c|c|c|c|}
\hline Types of Errors & Examples of Errors & $\begin{array}{l}\text { Number of Participants } \\
\text { committing the errors }\end{array}$ & Total Number of Errors \\
\hline Vocalic transfer errors & Betwin for Between & 4 & 65 \\
\hline Epenthesis Errors & Felm for Film & 3 & 55 \\
\hline Consonantal Replacement errors & Suborting for Supporting & 5 & 60 \\
\hline Cluster Simplification errors & Asesmant for Assessment & 4 & 40 \\
\hline Orthographic errors & Teckhnology for Technology & 4 & 40 \\
\hline Grapheme errors & Feture for Features & 4 & 50 \\
\hline Missing letters & Mening for Meaning & 5 & 58 \\
\hline Phonological errors & Dezine for Design & 5 & 55 \\
\hline Alteration errors & Skool for School & 4 & 50 \\
\hline
\end{tabular}

Again, in the second topic, the participants used high front vowels and reduced the mid vowels. The two most common types of errors in topic two are phonological errors, missing letters and consonantal replacement errors that come due the unfamiliarity of English spelling rules and pronunciation, such as when the word is supposed to use double letters or the learners do not pay attention to the silent letters.

\section{Discussion}

It is often more difficult for someone to learn something that is entirely new or very different from what they already know. Since English pronunciation system is very different from Arabic, this could help explain why English spelling poses such a problem for Arabic speakers. In the writing task, the majority of students made spelling errors related to prefixes, phonological errors, reduplication of letters, omission of letters, addition of letters, abbreviations, graphemes, and order errors, among others. The participants felt that the mistakes are due to influence from their mother tongue and the different pronunciation system between the two languages and the nature of English pronunciation itself, which support the finding of Al-Khairy (2013) from irregularities in the English spelling system and pronunciation.

Besides the mother-tongue interference, the nature of English itself is confusing, as perceived by the participants. However, this confusion can be attributed to their unfamiliarity with English. If they are familiar with English and have good content knowledge, they will not find the irregularities confusing. For instance, the participants felt that the inconsistencies between letters or letter combinations and corresponding sounds are troublesome for them in mastering English spelling.

The spelling problem is not limited to vowels. Several consonant sounds (and their corresponding letters) in English do not exist in Arabic, such as the English sounds /v/ and /p/. In comparing the performance of a Level 1 EFL learner and a Level 4 learner, certain patterns were found. For instance, the interviews with instructors revealed that in Arabic, certain pairs of English phonemes (i.e., /b/ and /p/, /f/ and /v/) led to problems because only one member of the pair was present in Arabic. The writing task confirmed that Saudi EFL learners often confused $/ \mathrm{b} /$ and $/ \mathrm{p} /$ or $/ \mathrm{f} /$ and $/ \mathrm{v} /$ in writing.

The common spelling errors identified in the writing task were phonological errors, epenthesis errors, altering words, incorrect grapheme phonics, missing letters, orthographic errors, cluster simplification, and vocal transfer errors. These errors were most often caused by a lack of understanding of basic writing techniques, spelling rules and pronunciation especially when the learners mixed up between the foreign language and their mother tongue and when the learners do not pay any attention to the English pronunciation system. For example, the students commonly confused words with similar spellings and did not understand how to systematize their writing. It is important for English language learners to understand the pronunciation system of English language because it helps them to communicate the meaning clearly.

\section{Conclusion}

This study has sought to provide insights into the spelling errors made by Saudi undergraduate EFL students while shading the light on the English pronunciation system as the main cause of Saudi students' spelling errors. Learners' unfamiliarity with English pronunciation system makes them confused in spelling the words correctly. As a result of this confusion, they turn to the system of their mother which is totally different from English and 
this makes them to produce major spelling errors which include vocalic transfer errors, epenthesis errors, consonantal replacement errors, cluster simplification errors, orthographic errors, missing letters, phonological errors and alteration errors.

Foreign language learners whose mother tongue is totally different from English (e.g., Arab learners of English) need to be made familiar with the English pronunciation system and they need to be made aware that they cannot apply the system of their mother tongue when using the foreign language as the two languages are linguistically different. This calls for direct teaching of English pronunciation system which is not currently practiced in Saudi education system. It is hoped that the findings revealed by this study will shed light into the importance of mastering English pronunciation system especially by Saudi students so that spelling errors caused by the pronunciation system can be reduced.

\section{References}

Algonhaim, A. (2014). Saudi university students' perceptions and attitudes towards communicative and non-communicative activities and their relationship to foreign language anxiety. Research Journal of English Language and Literature, 2, 83-101.

Al-Jarf, R. (2015). What ESL teachers should know about online writing tasks. English Language Teachers' Association of the Republic of Macedonia Journal, 1, 47-54

Al-Khairy, M. A. (2013). Saudi English-major undergraduates' academic writing problems: A Taif University Perspective. English Language Teaching, 6, 1-12. https://doi.org/10.5539/elt.v6n6p1

Almatarneh, A. H. M., Ab Rashid, R., \& Yunus, K. (2018). The academic writing experience of Jordanian postgraduate students at a university in Malaysia. Arab World English Journal, 9(3), 248-257. https://doi.org/10.24093/awej/vol9no3.17

Alsaawi, A. (2015). Spelling errors made by Arab learners of English. International Journal of Linguistics, 7 , 55-67. https://doi.org/10.5296/ijl.v7i5.8446

Anthony, J. L., \& D J. Francis. (2005). Development of phonological awareness. Current Directions in Psychological Science, 14, 255-259. https://doi.org/10.1111/j.0963-7214.2005.00376.x

Apel, K. (2011). What is orthographic knowledge? https://doi.org/10.1044/0161-1461(2011/10-0085

Apel, R. (2011). Transitional jobs program putting employment-based reentry programs into context. Criminology and Public Policy, 10, 939-942. https://doi.org/10.1111/j.1745-9133.2011.00781.x

Aslam, M S. (2015). Pronunciation as a stumbling block for the Saudi English learners: An analysis of the problems and some remedies. Theory and Practice in Language Studies, 5, 1578-1585. https://doi.org/10.17507/tpls.0508.06

Altamimi, D., Rashid, R.A., \& Elhassan, Y. (2018). A review of spelling errors in Arabic and non-Arabic contexts. English Language Teaching, 11(10), 88-94

Bourassa, D., \& Treiman, R. (2009). Spelling in children with dyslexia: Analyses from the Treiman-Bourassa early spelling test. Journal of Scientific Studies of Reading, 7, 309-333. https://doi.org/10.1207/S1532799XSSR0704_1

Bowers, P N., Kirby, J. R., \& Deacon, S. H. (2010). The effects of morphological instruction on literacy skills: A systematic review of the literature. Review of Educational Research, 80, 144-179. https://doi.org/10.3102/0034654309359353

Bruck, M., \& Treiman, R. (1990). Phonological awareness and spelling in normal children and dyslexics: The case of initial consonant clusters. Journal of Experimental Child Psychology, 50, 156-178. https://doi.org/10.1016/0022-0965(90)90037-9

Cook, V. (2004). The English writing system. London, UK: Edward Arnold.

Crompton, P. (2011). Article errors in the English writing of advanced L1 Arabic learners: The role of transfer.

Fadda, H. A. (2012). Difficulties in academic writing: From the perspective of King Saud University postgraduate students.

Farghaly, A., \& Shaalan, K. (2009). Arabic natural language processing: Challenges and solutions. ACM Transactions on Asian Language Information Processing, 8, 1-22. https://doi.org/10.1145/1644879.1644881

Ghabool, N., \& Kashef, S. H. (2012). Investigating Malaysian ESL students' writing problems on conventions, 
punctuation, and language use at secondary school level. Journal of Studies in Education, 2, 130-143. https://doi.org/10.5296/jse.v2i3.1892

Gillon, G. T. (2017). Phonological awareness: From research to practice. New York.

Gough, P. B., Juel, C., \& Griffith, P. L. (1992). Reading, spelling, and the orthographic cipher.

Jackson, H. (2014). Words and their Meaning. London: Routledge. https://doi.org/10.4324/9781315842004

James, C. (2013). Errors in language learning and use: Exploring error analysis. London: Routledge https://doi.org/10.4324/9781315842912

Kertesz, A., Cancelliere, A., \& Bub, D. (2017). Whole-word and Analytic Translation of Spelling to Sound in a Non-semantic Reader.

Khan, I A. (2011). Learning difficulties in English: Diagnosis and pedagogy in Saudi Arabia. Educational Research, 2, 1248-1257.

Khansir, A. A., \& Shahhoseiny, H. (2013). The study of written errors of EFL pre-university learners. Journal of Language Teaching and Research, 4, 1253-1258. https://doi.org/10.4304/jltr.4.6.1253-1258

Malcolm, D. (2009). Reading strategy awareness of Arabic-speaking medical students studying in English. System, 37, 640-651. https://doi.org/10.1016/j.system.2009.09.008

Mpiti, T. (2012). The nature of spelling errors of grade three isiXhosa background students in English first additional language. Unpublished master thesis, University of Fort Hare.

Ouellette, G., Martin-Chang, S., \& Rossi, M. (2017). Learning from our mistakes: Improvements in spelling lead to gains in reading speed. Scientific Studies of Reading, 21, 350-357. https://doi.org/10.1080/10888438.2017.1306064

Perveen, U., \& Akram, F. (2014). A comparative study to know the causes of spelling errors committed by learners of English at elementary level in Distract Kasur and Lahore in Pakistan. European Academic Research, 2, 2601-2622.

Puspandari, K. (2017). An analysis on spelling of inflectional nouns made by the seventh-grade students of SMPN 1 Loa Kulu. Jurnal Intelegensia, 2, 19-31.

Rajab, H. (2013). Developing speaking and writing skills of L1 Arabic EFL learners through teaching of IPA phonetic codes. Theory and Practice in Language Studies, 3, 653-659. https://doi.org/10.4304/tpls.3.4.653-659

Reed, D. K., Petscher, Y., \& Foorman, B. (2016). The contribution of vocabulary knowledge and spelling to the reading comprehension of adolescents who are and are not English language learners. Reading and Writing, 29, 633-657. https://doi.org/10.1007/s11145-015-9619-3

Rimbar, H. (2017). The influence of spell-checkers on students' ability to generate repairs of spelling errors. Journal of Nusantara Studies, 2(1), 1-12. http://dx.doi.org/10.24200/jonus.vol2iss1pp1-12

Saiegh-Haddad, E., \& Taha, H. (2017). The role of morphological and phonological awareness in the early development of word spelling and reading in typically developing and disabled Arabic readers. Dyslexia, 23, 345-371. https://doi.org/10.1002/dys.1572

Saigh, K., \& Schmitt, N. (2012). Difficulties with vocabulary word form: The case of Arabic ESL learners. System, 40, 24-36. https://doi.org/10.1016/j.system.2012.01.005

Santoro, L. E., Coyne, M. D., \& Simmons, D. C. (2006). The reading-spelling connection: Developing and evaluating a beginning spelling intervention for children at risk of reading disability. Learning Disabilities Research \& Practice, 21, 122-133. https://doi.org/10.1111/j.1540-5826.2006.00212.x

Sawalmeh, M. H. M. (2013). Error analysis of written English essays: The case of students of the preparatory year program in Saudi Arabia. English for Specific Purposes World, 14, 1-17.

Shintani, N., \& Ellis, R. (2013). The comparative effect of direct written corrective feedback and metalinguistic explanation on learners' explicit and implicit knowledge of the English indefinite article. Journal of Second Language Writing, 22, 286-306. https://doi.org/10.1016/j.jslw.2013.03.011

Solati, A. (2014). Psycholinguistic sources of English spelling errors. International Journal of Teacher Education, 3, 37-51.

Stanovich, K. E. (2000). Progress in understanding reading: Scientific foundations and new frontiers. 
Taha, T A. (2007). Arabic as 'a critical-need' foreign language in post-9/11 era: A study of students' attitudes and motivation. Journal of Instructional Psychology, 34, 150-160.

Treiman, R., \& Kessler, B. (2013). Learning to use an alphabetic writing system. Language Learning and Development, 9, 317-330. https://doi.org/10.1080/15475441.2013.812016

Wasowicz, J. (2007). What Do Spelling Errors Tell Us About Language Knowledge? Retrieved from https://www.speechpathology.com/articles/what-do-spelling-errors-tell-1226

\section{Copyrights}

Copyright for this article is retained by the author, with first publication rights granted to the journal.

This is an open-access article distributed under the terms and conditions of the Creative Commons Attribution license (http://creativecommons.org/licenses/by/4.0/). 